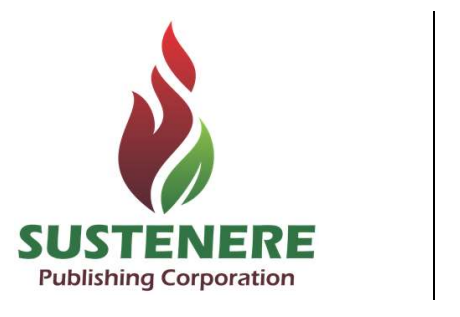

\section{DETERMINANTES DA INFLAÇÃO BRASILEIRA PÓS REGIME DE METAS PARA INFLAÇÃO: UMA ANÁLISE DOS PRINCIPAIS ÍNDICES PARA A DÉCADA DE 2000}

\section{RESUMO}

Essa pesquisa apresenta um estudo analítico dos principais índices de inflação no Brasil, destacando o Índice de Preços ao Consumidor Amplo (IPCA), na década de 2000 , bem como seus grupos, subgrupos e importantes desagregações, a fim de verificar quais os componentes que mais pressionaram os níveis de preços. Numa abordagem geral os movimentos do IPCA e seus componentes são os mais representativos do que ocorreu com a inflação brasileira na década de 2000 , ou seja, os preços administrados, principalmente na primeira metade da década, e depois, o grupo alimentos, se destacaram como os principais pressionadores do índice.

PALAVRAS-CHAVES: IPCA; Inflação; Década de 2000.

\section{DETERMINANTS OF BRAZILIAN INFLATION AFTER INFLATION TARGETING REGIME: AN ANALYSIS OF THE MAIN INDICES FOR THE 2000}

\section{ABSTRACT}

This research presents an analytical study of the main inflation rates in Brazil, giving particular attention to the Consumer Price Index (IPCA), in the 2000s, and their groups, subgroups and major breakdowns, in order to ascertain which components most influenced price levels. In a general approach IPCA movements and their components are the most representative of what happened with Brazilian inflation in the 2000s, administered prices played a fundamental role in the behavior of inflation, especially in the first half of the decade, after this period the group is pushing food prices more significantly.

KEYWORDS: IPCA; Inflation; 2000 Decade.
Revista Brasileira de

Administração Científica, Aquidabã, v.6, n.1, Jan, Fev, Mar, Abr, Mai, Jun 2014.

\section{ISSN 2179-684X}

\section{SECTION: Articles}

TOPIC: Finanças e Contabilidade

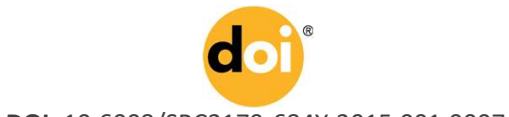

DOI: 10.6008/SPC2179-684X.2015.001.0007

Mateus Boldrine Abrita

Universidade Estadual de Mato Grosso do Sul, Brasil http://lattes.cnpq.br/4881303482310816

mateusabrita@hotmail.com

Received: 06/04/2015

Approved: 14/10/2015

Reviewed anonymously in the process of blind peer.

Referencing this:

ABRITA, M. B.. Determinantes da inflação brasileira pós regime de metas para inflação: uma análise dos principais índices para a década de 2000. Revista Brasileira de Administração Científica, Aquidabã, v.6, n.1, p.114-132, 2015. DOI: http://dx.doi.org/10.6008/SPC2179$\underline{684 X .2015 .001 .0007}$ 


\section{INTRODUÇÃO}

A taxa de inflação resultante de determinado índice tem como objetivo geral auferir os movimentos médios dos preços de uma cesta de bens e serviços, em dado período de tempo. Existem diversos mecanismos e cestas de bens que podem ser incorporados nas análises de preços, como aspectos de localização geográfica, produtores, consumidores, varejo e atacado. Porém é importante salientar que devido à complexidade do fenômeno inflacionário, quando são realizadas as agregações nos índices, algum prejuízo na análise das trajetórias de cada segmento específico certamente ocorre. Assim é de grande relevância que os estudos a respeito do fenômeno da inflação, considerem essas especificidades em suas observações.

A questão da inflação é um dos temas mais debatidos no estudo das ciências econômicas, especialmente em países caracterizados por processos importantes de aceleração inflacionária, como o Brasil. Assim, a sua melhor compreensão pode contribuir para que os agentes econômicos e formuladores de políticas tomem boas decisões e evitem custos e externalidades indesejadas, que uma visão míope pode ocasionar. Desse modo, este artigo tem por objetivo analisar os principais índices de inflação no Brasil na última década, bem como seus grupos, subgrupos e importantes desagregações, a fim de verificar quais os componentes que mais pressionaram os níveis de preços.

\section{REVISÃO TEÓRICA}

\section{Panorama Geral dos Principais índices de Inflação no Brasil}

Apesar do sucesso inequívoco do plano real em estabilizar a moeda, a inflação brasileira na década, ainda está em patamares elevados se comparado com outras importantes economias. A tabela 1 mostra sinteticamente alguns dos principais índices de inflação do Brasil:

Tabela 1: Principais índices de inflação no Brasil, 2000 a 2011 em (\% a.a.).

\begin{tabular}{|l|l|l|l|l|l|l|l|l|l|l|l|}
\hline & IPC (FIPE) & INPC & IPCA & IGP-DI & IGP-M & IPA-EP & IPC (FGV) & IGP-OG & ICV-SP & INCC \\
\hline 2000 & 4.37 & 5.27 & 5.97 & 9.81 & 9.95 & 12.06 & 6.21 & 9.78 & 7.21 & 7.66 \\
\hline 2001 & 7.12 & 9.44 & 7.67 & 10.40 & 10.38 & 11.87 & 7.94 & 10.38 & 9.43 & 8.85 \\
\hline 2002 & 9.91 & 14.74 & 12.53 & 26.41 & 25.31 & 35.41 & 12.18 & 26.31 & 12.93 & 12.87 \\
\hline 2003 & 8.16 & 10.38 & 9.30 & 7.67 & 8.71 & 6.26 & 8.93 & 7.69 & 9.56 & 14.42 \\
\hline 2004 & 6.56 & 6.13 & 7.60 & 12.14 & 12.41 & 14.67 & 6.27 & 12.11 & 7.70 & 11.02 \\
\hline 2005 & 4.52 & 5.05 & 5.69 & 1.22 & 1.21 & -0.97 & 4.93 & 1.25 & 4.53 & 6.84 \\
\hline 2006 & 2.53 & 2.81 & 3.14 & 3.79 & 3.83 & 4.29 & 2.05 & 3.79 & 2.56 & 5.04 \\
\hline 2007 & 4.38 & 5.16 & 4.46 & 7.89 & 7.75 & 9.44 & 4.60 & 7.87 & 4.79 & 6.15 \\
\hline 2008 & 6.16 & 6.48 & 5.90 & 9.10 & 9.81 & 9.80 & 6.07 & 9.09 & 6.11 & 11.87 \\
\hline 2009 & 3.66 & 4.11 & 4.31 & -1.43 & -1.72 & -4.08 & 3.95 & -1.40 & 4.04 & 3.25 \\
\hline 2010 & 6.39 & 6.47 & 5.91 & 11.30 & 11.32 & 13.85 & 6.24 & 11.27 & 6.91 & 7.77 \\
\hline 2011 & 5.80 & 6.08 & 6.50 & 5.00 & 5.10 & 4.12 & 6.36 & 5.01 & 6.11 & 7.49 \\
\hline
\end{tabular}


Cabe salientar, primeiramente, algumas considerações a respeito das características de cada índice. O Índice de preços ao consumidor da Fundação Instituto de Pesquisas Econômicas (IPC-FIPE) mensura os preços para a cidade de São Paulo ao consumidor, considerando famílias com renda mensal de até vinte salários mínimos. Já o Índice Nacional de Preços ao Consumidor (INPC) medido pelo Instituto Brasileiro de Geografia e Estatística (IBGE) considera famílias com renda mensal entre um e cinco salários mínimos, cujo chefe é assalariado em sua ocupação principal e residente de área urbana, possuindo abrangência geográfica de várias regiões metropolitanas do Brasil.

O Índice Nacional de Preços ao Consumidor Amplo (IPCA) auferido também pelo IBGE é o índice oficial do Governo Federal do Brasil, inclusive para as metas inflacionárias adotadas pelo Banco Central do Brasil (BCB), a pesquisa abrange famílias com rendimentos mensais entre um e quarenta salários mínimos, não fazendo distinção da fonte de rendimentos e possui abrangência geográfica de várias regiões metropolitanas do Brasil. O Índice Geral de Preços Disponibilidade Interna (IGP-DI) é calculado pela Fundação Getulio Vargas (FGV) sendo resultante de uma média aritmética ponderada de três índices; Índice de Preços no Atacado (IPA) equivale a 60\%, Índice de Preços ao Consumidor (IPC) equivale a $30 \%$ e o Índice Nacional de Custo da Construção (INCC) ponderando $10 \%$ do IGP-DI. Como o índice considera a disponibilidade interna, os preços dos produtos exportados não são considerados.

O Índice Geral de Preços do Mercado (IGP-M) é medido pela FGV e largamente utilizado como índice de correção de contratos de aluguéis além de algumas tarifas de energia. Possui a mesma composição do IGP-DI, porém os dias considerados mudam, no caso do IGP-M o período vai do dia vinte e um do mês anterior até o dia vinte do mês de referência, já o IGP-DI analisa, do dia um ao trinta do mês de referência. No âmbito do atacado, o Índice de Preços por Atacado segundo Estágio de Processamento (IPA-EP) mede os preços praticados em nível atacadista, que antecedem o nível varejista, é calculado pela FGV. O Índice de Preços ao Consumidor elaborado pela FGV (IPC-FGV) reflete o nível de preços no varejo, considerando famílias com renda de um até trinta e três salários mínimos, possui abrangência em São Paulo e Rio de Janeiro. Já o Índice Geral de Preços Oferta Global (IGP-OG) considera a trajetória do nível de preços dos produtos ofertados no mercado interno e externo do país, possuindo abrangência nacional e calculado pela FGV. Auferido pelo Departamento Intersindical de Estatística e Estudos Socioeconômicos (DIEESE), o Índice de Custo de Vida de São Paulo (ICV-SP) afere a evolução dos preços do custo de vida das famílias na cidade de São Paulo com renda mensal familiar de um até trinta salários mínimos. O Índice Nacional de Custo da Construção (INCC) é calculado pela FGV e analisa o nível de preços do custo de construções habitacionais.

Destaque-se que o grave problema inflacionário que assolou a economia brasileira, fez com que os diversos índices de preços fossem construídos ao longo do tempo com diferentes finalidades. Segundo o BCB (2012), o IPC-Fipe, por exemplo, foi criado pela Prefeitura Municipal de São Paulo com o objetivo de reajustar os salários dos servidores municipais. O IGP-M foi 
criado para ser usado no reajuste de operações financeiras, especialmente as de longo prazo, e o IGP-DI para balizar o comportamento dos preços em geral da economia. O INPC é o índice balizador dos reajustes de salário, enquanto o IPCA corrige os balanços e demonstrações financeiras trimestrais e semestrais das companhias abertas, além de ser o medidor oficial da inflação no país. Após uma breve explicação a cerca dos elementos fundamentais de alguns dos mais importantes índices de inflação no Brasil, apresentados na tabela 1, o gráfico 2 revela a trajetória da inflação mensurada pelos diferentes índices de preços, no período de 2000 até 2011.

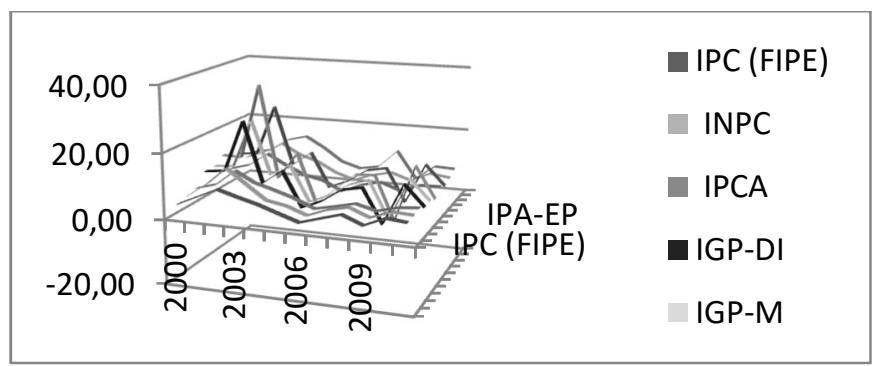

Gráfico 1: Principais índices de inflação no Brasil, 2000 a 2011 em (\% a.a.).

As variações percentuais dos índices de preços revelam que no início da década, principalmente de 2001 até 2003, os índices de inflação, de um modo geral, orbitaram em níveis mais elevados que na média do período analisado. Cabe destacar o ano de 2002, ao qual, a maioria dos índices tiveram seus picos, o IPA-EP atingiu 35,41\%, seguido de IGP-DI 26,41\%, IGPOG 26,31\% e IGP-M 25,31\%. Os demais índices apresentaram valores praticamente superiores a 10\%. O IPC da FIPE apresentou seu pico em 2002 e seu vale em 2006 alternando valores entre 2,53\% e 9,91\%. Já o INPC apresentou seu valor máximo no ano de 2002 com 14,74\% e seu valor mais baixo em 2006 com 2,81\%. O IPCA apresentou trajetória semelhante, seu pico foi 12,53\% em 2002 e apresentou menor valor em 2006 com 3,14\%. Outro índice de preços ao consumidor o IPC da FGV também exibiu seu valor máximo em 2002 com 12,18\% e seu vale em 2006 com 2,05\%. Nesse mesmo ritmo, o ICV-SP apresentou 12,93\% em 2002 e 2,56\% em 2006 e um pequeno pico em 2010 e 2011. Desse modo, os índices de preços ao consumidor no Brasil tiveram trajetórias semelhantes, ao menos nos picos e vales, demonstrando uma forte pressão inflacionária no ano de 2002 e um arrefecimento no ano de 2006. Uma explicação a ser considerada para esses movimentos pode ser observada no gráfico 2 .

A taxa de câmbio influencia a inflação basicamente por três vias, custos de produção, bens finais importados e comercializáveis. As trajetórias dos índices de inflação IGP-DI e IPCA aparentemente apresentam uma relação positiva com a taxa de câmbio. É importante ressaltar que no período de 2001 até 2003, no qual os índices da tabela 1 apresentaram seus maiores valores, a taxa de câmbio também esteve em patamares mais elevados. Trata-se de mais uma evidência favorável a um dos mais marcantes fatos estilizados da economia brasileira desde o Plano Real: a elevada influência da taxa de câmbio sobre a inflação (OREIRO et al., 2008; FERRARI FILHO et al., 2009; MODENESI, 2005). 

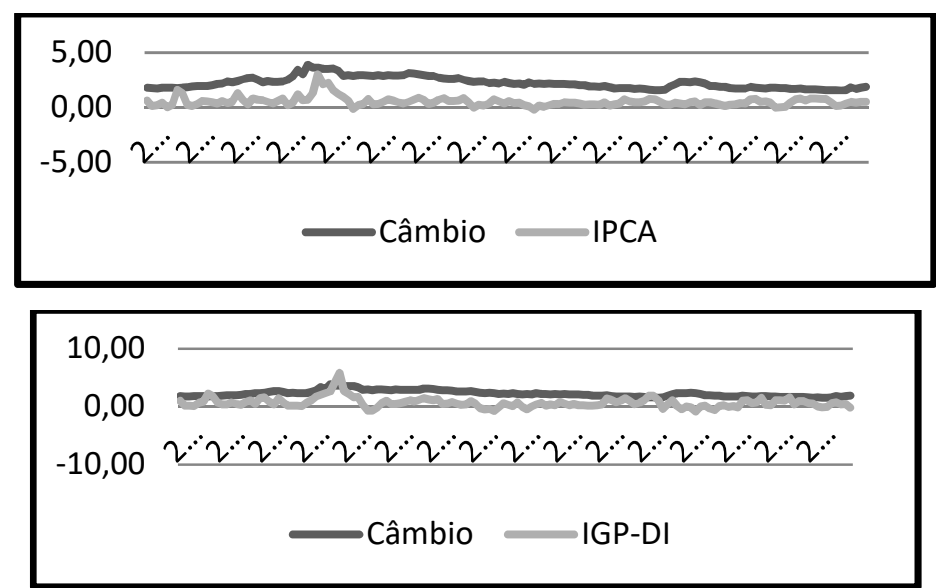

Gráfico 2: Taxa de câmbio - R\$ / US\$, IPCA e IGP-DI em (- var. -\% a.m.)

Já no ano de 2008, embora tenha havido desvalorização cambial, esta não acarretou o mesmo efeito do início da década, talvez por pressões deflacionárias de outros componentes dos índices não diretamente determinados pelo câmbio. O período caracterizado por apreciação cambial, que vai de 2003 até meados de 2008, é acompanhado por um arrefecimento dos índices de preços do gráfico 2, revelando a importância da relação câmbio e nível de preços. A evolução dos preços das commodities e da cesta básica observada no gráfico abaixo também pode ser um fator explicativo da evolução dos níveis de preços no Brasil.

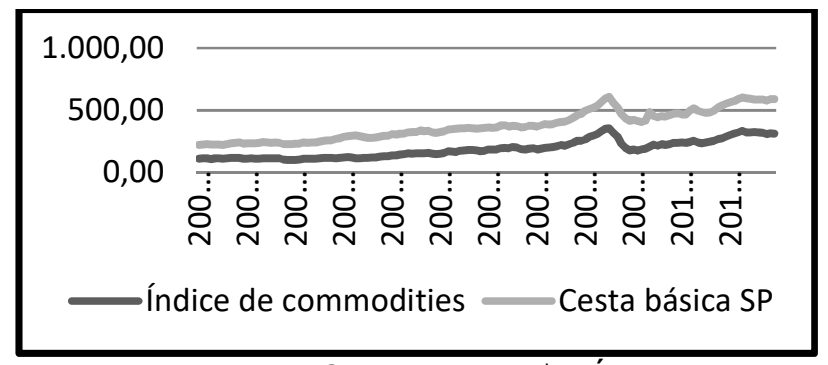

Gráfico 3: Cesta básica - município de São Paulo - R\$ e Índice commodities -geral - preço.

O gráfico 3 mostra o valor da cesta básica no município de São Paulo, em reais, calculado pelo DIEESE, em comparação com um índice de commodities elaborado pelo Ipea (jan. $2002=$ 100). Cabe ressaltar que o mais importante no gráfico é analisar as evoluções dos dois preços, que apresentam uma relação estreita, já que os dois representam preços básicos da economia. Assim pode ser observada uma trajetória de alta ao longo do período, com destaque para ano de 2008. Uma afirmação categórica a respeito do impacto da alta dos preços das commodities sobre o nível de inflação é bastante complexo, principalmente em países como o Brasil, que é um grande exportador nessa área. Isso porque é necessário separar os efeitos das elevações nos preços dos alimentos e demais produtos relacionados diretamente com as commodities, do efeito indireto que ocorre devido a apreciação cambial que essas exportações provocam. De qualquer forma, são duas variáveis extremamente importantes para explicar a evolução dos níveis de preços no Brasil. Outro elemento relevante para observar o panorama da inflação brasileira na 
década de 2000 é o salário mínimo, no gráfico 4, é apresentado a evolução do salário mínimo real em reais ao longo da década:

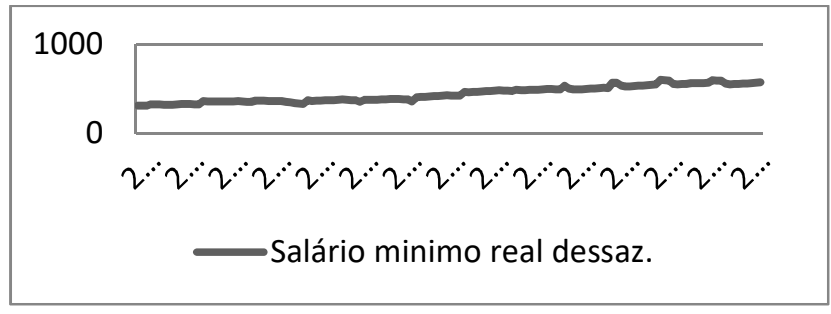

Gráfico 4: Salário mínimo real dessazonalizado.

Uma das consequências mais significativas da valorização do salário mínimo ocorre na distribuição de renda, redução da pobreza na economia, além de influenciar pagamentos previdenciários e indiretamente aumentar o poder de barganha dos trabalhadores nas negociações dos demais contratos. O gráfico 4 mostra ganhos reais no salário mínimo ao longo da década analisada, certamente influenciando setores como de serviços, despesas pessoais e demais áreas tanto no lado da demanda como de elevação nos custos.

A inflação de salários é resultante da negociação entre trabalhadores e empresários. Assim se os trabalhadores individual ou coletivamente, obterem aumentos reais, acima da produtividade, somada a capacidade de repasse aos preços por parte dos empresários, a inflação será pressionada para cima. Outra abordagem interessante a respeito do salário mínimo é sua comparação com o setor externo, assim o gráfico 5 mostra a evolução do salário com paridade do poder de compra em relação aos Estados Unidos.

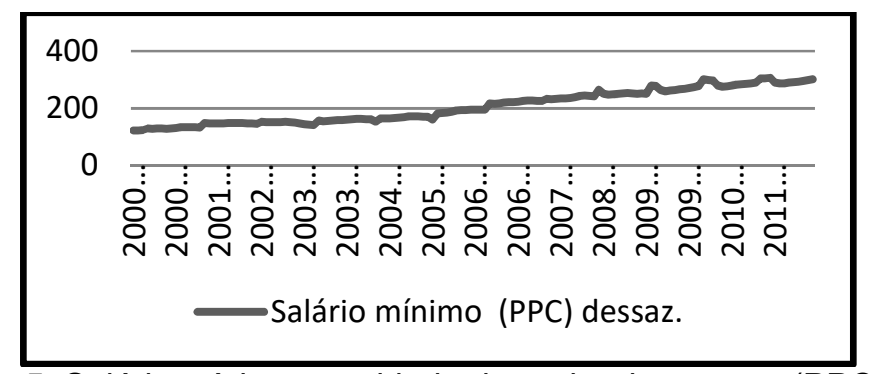

Gráfico 5: Salário mínimo - paridade do poder de compra (PPC) - US\$

Essa série elaborada pelo IPEA reflete em cada mês o preço nos EUA de uma mesma cesta de bens, que se podia adquirir com um salário mínimo no Brasil. A análise do gráfico 5 mostra que o salário mínimo no Brasil obteve ganhos de paridade no poder de compra ao longo do período observado. Realizado um panorama geral dos principais preços, salários e índices da economia brasileira na década de 2000 , os próximos tópicos buscam analisar os principais índices de inflação, dando ênfase em suas decomposições, a fim de verificar qual ou quais os componentes mais pressionaram os níveis de preços no país. Inicialmente será abordado o índice oficial do Governo Federal do Brasil, o IPCA, seguido por INPC, IPC da Fipe e alguns índices por atacado. 


\section{Análise do IPCA e suas Decomposições}

O IPCA é elaborado pelo IBGE, sendo um dos índices mais importantes para o país, serve de referência para sistema de metas de inflação a partir de 1999 adotado pelo Banco Central do Brasil (BCB). Barbosa-Filho (2007) elenca os elementos principais da base institucional do regime de metas para inflação no Brasil: constituído por um conselho monetário nacional; em junho de cada ano o conselho estabelece as metas inflacionárias dos próximos dois anos, considerando a taxa do IPCA como referencia; o Banco Central do Brasil é responsável por cumprir a meta, porém não é especificado a estratégia nem os instrumentos; o Comitê de política monetária define a taxa básica de juros Selic baseada na meta de inflação; existe um intervalo de tolerância para a meta inflacionária; por fim, se a meta não for alcançada o presidente do BCB deve escrever um pronunciamento ao Ministro da Fazenda explicando as causas do fracasso.

Assim, o IPCA está institucionalizado como referência no regime de metas de inflação do Brasil, ele possui quatro níveis principais de agregação elaborados pelo próprio IBGE sendo eles: grupos, subgrupos itens e subitens. A agregação grupos é a mais geral e por sua vez está também dividida em: alimentação e bebidas, habitação, artigos de residência, vestuário, transportes, saúde e cuidados pessoais, despesas pessoais, educação e comunicação. Os pesos que cada grupo possui são orientados pela Pesquisa de Orçamentos Familiares (POF), a qual mensura o consumo familiar típico da população com renda até quarenta salários mínimos.

Também é importante ressaltar a decomposição realizada BCB, a instituição divide o IPCA, de um modo geral, em preços livres compostos por bens comercializáveis e não comercializáveis e por preços monitorados (administrados por contrato). Os bens comercializáveis são fortemente influenciados pelo setor externo e taxa de câmbio, já os não comercializáveis ou non-tradables são orientados e produzidos para mercado interno, um importante exemplo são os serviços. Os bens administrados por contrato ou monitorados estão diretamente relacionados com a administração pública, por exemplo, tarifas, preços de combustíveis e energia. Todas essas divisões serão abordadas nos gráficos e tabelas a seguir, inicialmente é importante mensurar o impacto dos preços administrados na evolução do IPCA como evidencia o gráfico 6 .

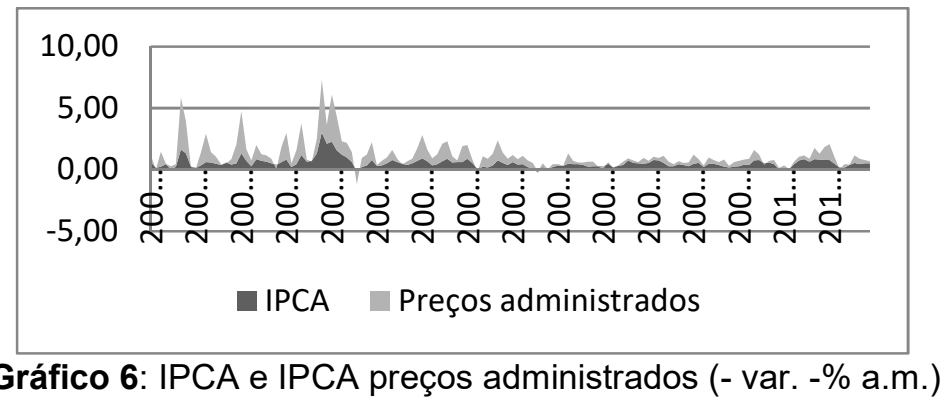

Os preços administrados por contrato ou monitorados possuem uma sensibilidade menor as flutuações entre demanda e oferta, porém não são necessariamente diretamente regulados pelo poder público. Entretanto, é considerável o peso do governo nas flutuações desses preços. O 
gráfico 6 revela que os preços administrados apresentaram variações para cima superiores aos demais componentes do índice de inflação durante quase todo o período de análise. Isso revela o peso que os preços orientados pela administração pública exercem sobre a inflação brasileira, sendo um dos principais elementos que pressionaram a inflação para cima no período. A seguir, é analisada a relação entre os preços livres e o IPCA. Os preços livres são de um modo geral mais 'flexíveis' e são mais sensíveis aos movimentos de oferta e demanda na economia, como pode ser observado no gráfico 7 .

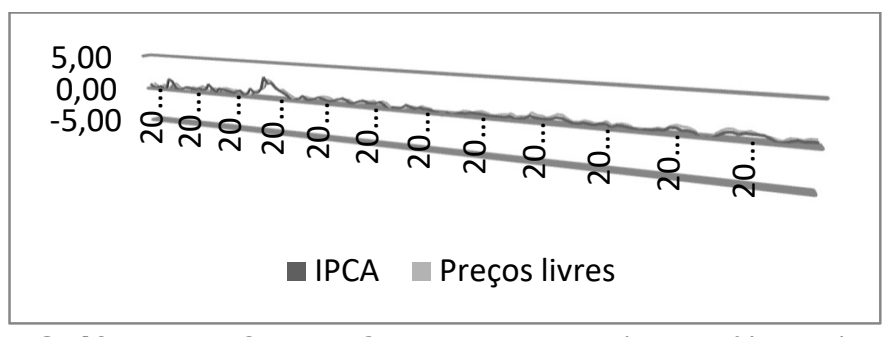

Gráfico 7: IPCA e IPCA preços livres (- var. -\% a.m.).

O gráfico 7 mostra uma tendência geral dos preços livres em pressionar a inflação para baixo ou manter uma evolução próxima ao índice geral, considerando duas fases. A primeira de 2000 até 2006, a qual, apenas em alguns períodos, Os preços livres apresentaram uma trajetória superior ao nível do IPCA, pressionando o índice para baixo em grande parte do período, já a fase de 2007 até 2011 , os preços livres apresentaram uma trajetória mais próxima ao índice geral e em alguns momentos exerceram pressão de alta na inflação. Outra análise importante a respeito da decomposição do IPCA está relacionada com os preços de bens e serviços que podem ou não ser comercializados com o setor externo. O gráfico 8 mostra as trajetórias das variações percentuais dos preços comercializáveis, não comercializáveis e o IPCA, como pode ser observado.

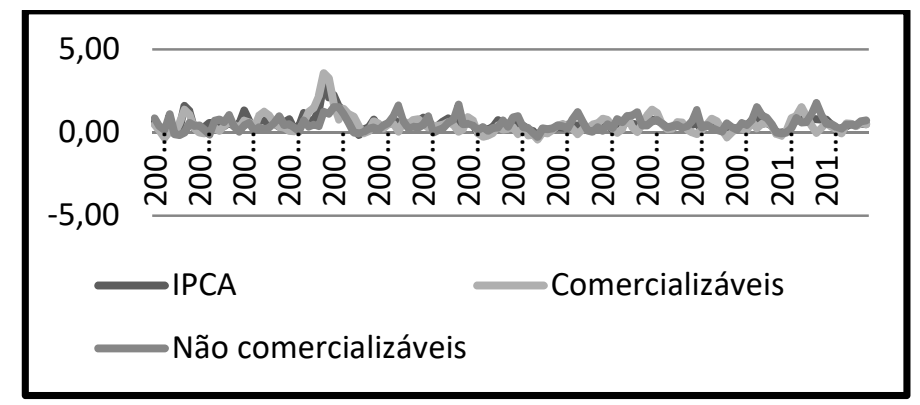

Gráfico 8: IPCA, IPCA comercializáveis e não comercializáveis (var. -\% a.m.)

O gráfico 8 mostra que os comercializáveis pressionaram os preços para cima de maneira mais aguda no início da década, atingindo um pico em 2002. Já os preços dos não comercializáveis apresentam uma trajetória de variação semelhante ao longo do período analisado alternando momentos em que se situa acima e abaixo da linha do IPCA. Com o propósito de investigar quais elementos do IPCA mais pressionaram os preços na década, a tabela 2 mostra as evoluções percentuais acumuladas em doze meses de quatro grupos fundamentais para o entendimento da composição da inflação dentro do IPCA. Os grupos são: Alimentos e bebidas, Serviços, Monitorados ou administrados por contratos e Industriais, a 
segunda coluna mostra os pesos médios de 2000 até 2010 dos agrupamentos sobre o índice e por fim o IPCA cheio.

Tabela 2: IPCA e suas decomposições 2000 a 2010.

\begin{tabular}{|c|c|c|c|c|c|c|c|c|c|c|c|c|}
\hline Grupos & $\begin{array}{l}\text { Peso } \\
\text { médio }\end{array}$ & $\begin{array}{l}200 \\
0\end{array}$ & $\begin{array}{l}200 \\
1\end{array}$ & 2002 & $\begin{array}{l}200 \\
3\end{array}$ & $\begin{array}{l}200 \\
4\end{array}$ & $\begin{array}{l}200 \\
5\end{array}$ & $\begin{array}{l}200 \\
6 \\
\end{array}$ & $\begin{array}{l}200 \\
7\end{array}$ & $\begin{array}{l}200 \\
8\end{array}$ & $\begin{array}{l}200 \\
9\end{array}$ & $\begin{array}{l}201 \\
0\end{array}$ \\
\hline $\begin{array}{l}\text { Alimentos e } \\
\text { bebidas }\end{array}$ & 22.3 & 4.9 & 11.1 & 20.7 & 8.5 & 4.7 & 2.8 & 1.7 & 10.8 & 11.1 & 3.2 & 10.4 \\
\hline Serviços & 23 & 3.2 & 4.9 & 5.5 & 7.2 & 5.5 & 6.8 & 5.5 & 5.2 & 5.5 & 5.5 & 7.6 \\
\hline Administrados & 31.5 & 11.1 & 9.5 & 14.7 & 13 & 9.8 & 8.6 & 4.2 & 1.7 & 3.2 & 4.9 & 3.1 \\
\hline Industriais & 23.1 & 5.1 & 6.2 & 9.6 & 8 & 9 & 4.2 & 1.4 & 2.1 & 4.1 & 2.8 & 3.5 \\
\hline IPCA & 100 & 5.97 & 7.67 & $\begin{array}{l}12.5 \\
3\end{array}$ & 9.3 & 7.6 & 5.67 & 3.13 & 4.46 & 5.9 & 4.31 & 5.91 \\
\hline
\end{tabular}

Os preços administrados foram os mais significativos, pressionando a inflação no período de 2000 até 2005, apresentando $14,7 \%$ no ano de 2002, enquanto os serviços subiram apenas $5,5 \%$ nesse mesmo ano. O segundo maior grupo que mais impactou o nível de preços no período de 2000 até 2005 foi o dos alimentos e bebidas, seu pico foi ainda maior que o dos administrados no ano de 2002 alcançando $20,7 \%$. Os preços industrializados, apesar de uma aceleração em 2001 e 2002, talvez fruto da depreciação cambial do período, fica em terceiro lugar nesse período de análise situando-se a frente somente do grupo serviços, que aparece, nessa abordagem como o grupo de menor pressão inflacionária no IPCA, dado o período.

Na segunda metade da década, a partir do ano de 2006, os preços dos administrados sofrem um arrefecimento e o grupo alimentos e bebidas passam a exercer a maior pressão inflacionária do período. Como mostrado no gráfico 3 , o preços das commodities sofrem fortes altas nos mercados internacionais, esse fenômeno pode explicar parte das elevações nos preços dos alimentos internamente. Após 2006, as variações do grupo alimentos e bebidas atingiram patamares superiores a $10 \%$, salvo 2009 , é importante também destacar que o grupo serviços apresenta um valor elevado de $7,6 \%$ em 2010. Os preços industriais tiveram valores relativamente baixos em 2006 com 1,4\%, 2007 2,1\% e 2009 2,8\%. De um modo geral, no período de 2000 até 2010, o grupo dos preços administrados foi o que mais pressionou o índice de inflação para cima, seguido do grupo alimentos e bebidas. No último ano da série, o grupo serviços dá indícios de aceleração, porém, junto com os preços industriais, apresentou evolução em patamares abaixo dos dois primeiros grupos. Essa conclusão fica clara quando se analisa o gráfico 9:

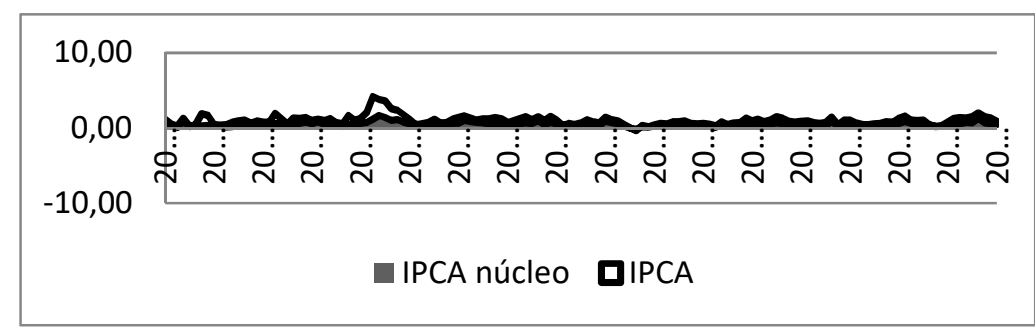

Gráfico 9: IPCA e IPCA núcleo por exclusão de preços administrados e alimentos (var. -\% a.m.) 
Dado o comportamento volátil dos índices de inflação cheios, a ideia do núcleo do índice de preços foi sendo desenvolvida e utilizada pelas autoridades monetárias e agentes econômicos. Em geral, os Bancos Centrais buscam analisar o comportamento de tendência inflacionária, o que pode ser deturpado pelos índices cheios, aos quais são influenciados por fatores temporários e isolados que não fazem necessariamente parte da inflação de médio e longo prazo. O gráfico 9 mostra a evolução do IPCA e de seu núcleo por exclusão dos preços administrados e alimentos. Por meio das evoluções dos dois índices fica evidente a significativa participação dos preços administrados e do grupo alimentos na composição do IPCA. Após uma análise detalhada dos componentes do IPCA, o tópico a seguir tem como objetivo investigar quais os grupos e componentes exerceram maior pressão sobre o INPC.

\section{Análise do INPC e suas Composições}

O Índice Nacional de Preços ao Consumidor (INPC) medido pelo IBGE é composto por nove subgrupos: alimentação, habitação, educação, artigos de residência, vestuário, transporte, comunicação, saúde e cuidados pessoais e despesas pessoais. Inicialmente é abordado o grupo alimentos no gráfico 10. O gráfico 10 mostra a evolução dos preços do INPC em relação ao grupo alimentos. No período de meados de 2000 até meados de 2003, os preços dos alimentos exercem forte pressão inflacionária sobre o índice, apresentando trajetória superior ao INPC em grande parte do período. A partir de meados de 2003 até meados de 2006, os preços dos alimentos sofrem um arrefecimento e caminham, ora junto com o índice geral, ora exercendo impacto negativo. No final de 2006 até meados de 2008, o grupo volta a pressionar os preços em patamares consideráveis, após 2008 passa por um período de acomodação. Destaque para o biênio 2010 e 2011, ao qual o índice alterna impactos consideráveis positivos e negativos.

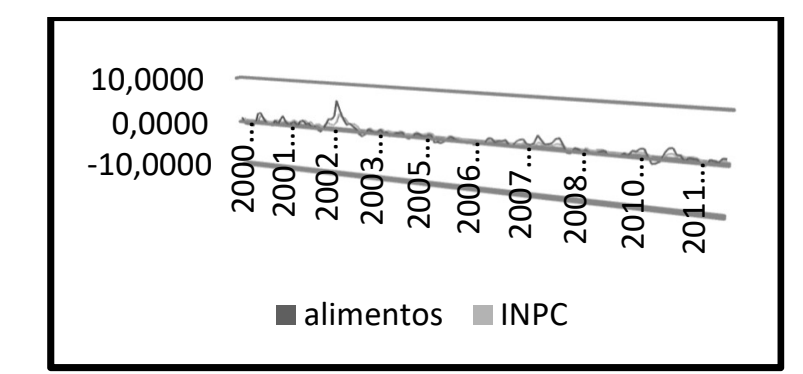

Gráfico 10: INPC e grupo alimentos (var. -\% a.m.).

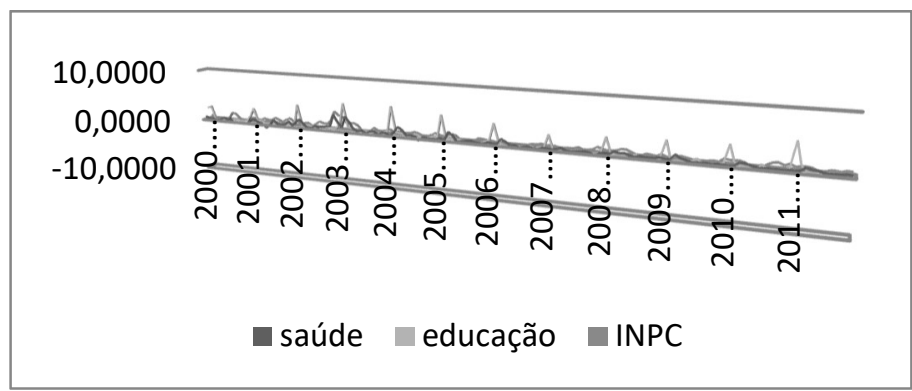

Gráfico 11: INPC, grupo educação, leitura e papelaria e saúde e cuidados pessoais (var. -\% a.m.) 
O grupo educação apresenta fortes reajustes no início de cada ano e depois se acomoda, exercendo até um impacto negativo no índice geral, já o grupo saúde mostra uma trajetória próxima ao índice geral, sendo que, de 2000 até 2004, caminha abaixo das variações do INPC, após 2004 e até 2006 apresenta alguns reajustes sazonais consideráveis, porém depois alterna sua evolução para momentos muito próximos ao índice e momentos de pressões de baixa. De um modo geral, os impactos do grupo educação foram altos, já o grupo saúde apresentou uma trajetória mais relacionada com pressões de baixa do que pressões inflacionárias se comparado com o INPC. Outro importante grupo para análise da inflação é o grupo habitação que será apresentado no gráfico 12. O gráfico 12 mostra a relação entre as variações percentuais do grupo habitação em relação com o INPC. No período de 2000 até 2003, a pressão de alta desse grupo foi mais intensa, passando para uma acomodação nos anos seguintes, ao qual alterna momentos de alta e de baixa em relação a evolução normal do INPC.

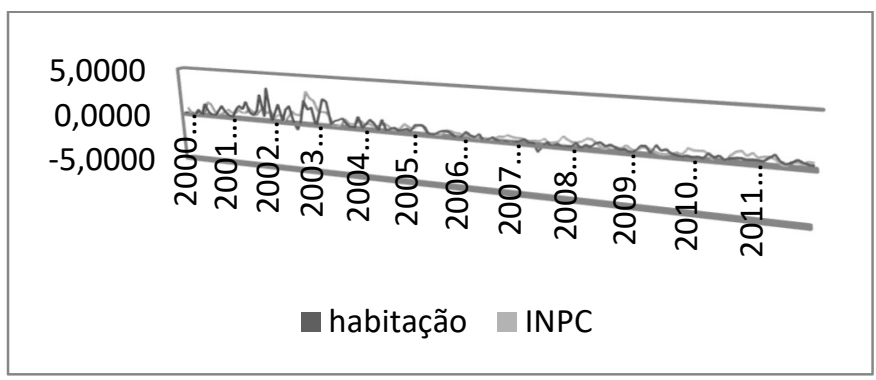

Gráfico 12: INPC e grupo habitação (var. -\% a.m.)

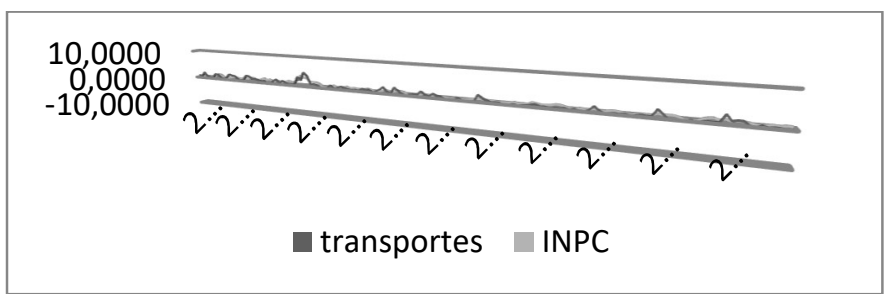

Gráfico 13: INPC e grupo transportes (var. -\% a.m.).

A interação entre o grupo transportes e o INPC é observada no gráfico 13. Esse grupo apresenta picos de elevações ao longo de todo o período. A partir do ano 2000 até 2003, ocorre uma pressão considerável, sendo que em 2003, ocorre o pico de toda a década. De meados de 2003 a 2004, os preços relacionados aos transportes apresentam um arrefecimento e caminha em trajetória próxima ao índice, após esse período até o final da década, o grupo apresenta um comportamento alternando fortes reajustes e acomodações. Mas de um modo geral é significativo o impacto desse grupo no INPC. Agora serão apresentados abaixo os agrupamentos que, de um modo geral, exerceram pressão de baixa sobre o INPC.

O gráfico 14 mostra a trajetória dos grupos vestuário, artigos de residência, despesas pessoais e comunicação em relação ao INPC. Os quatro apresentam uma trajetória geral de alternância, em caminhar próximo ao índice cheio, ou exercer pressão de baixa ao longo do período analisado. Desse modo, cabe dividir os grupos em dois, o primeiro, apesar de alternar momentos de pressão inflacionária e arrefecimentos, de um modo geral exerceu pressões 
positivas sobre o INPC ao longo da década, são eles: alimentos, saúde, educação, habitação e transportes. Já o segundo grupo exerceu um comportamento claro no sentido de exercer impactos negativos no índice cheio, são eles: vestuário, artigos de residência, despesas pessoais e comunicação. A fim de aprofundar as análises, outro índice de preços ao consumidor será investigado no próximo tópico bem como seus componentes, com o propósito de retirar algumas conclusões a cerca dos elementos que pressionaram positiva ou negativamente o índice.

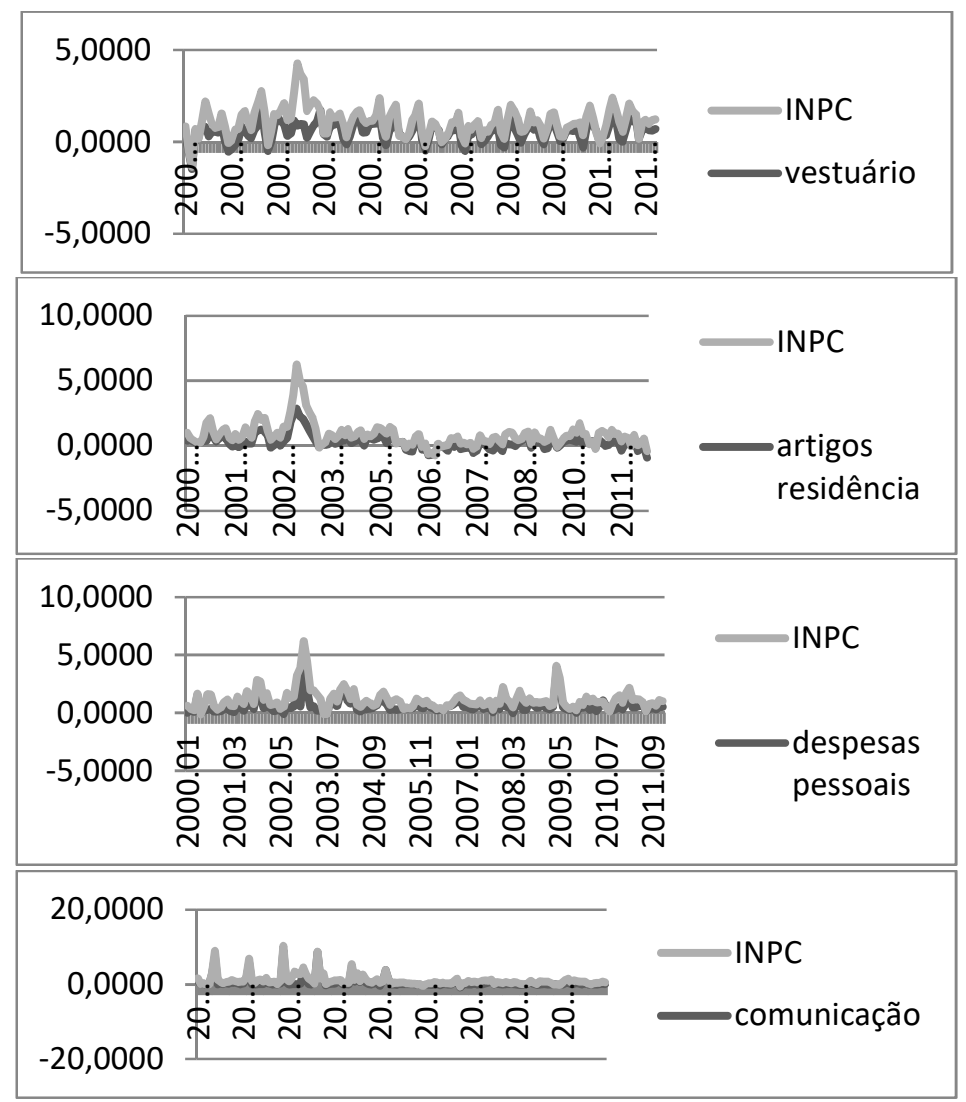

Gráfico 14: INPC, grupo vestuário, artigos de residência, despesas pessoais e comunicação (var. -\% a.m.)

\section{Análise do IPC-FIPE e suas Composições}

O Índice de preços ao consumidor da Fundação Instituto de Pesquisas Econômicas (IPCFIPE) mensura os preços para a cidade de São Paulo ao consumidor, utiliza a pesquisa de orçamento familiar (POF) para compor os grupos de despesa, considerando famílias com renda mensal de até vinte salários mínimos. O período de coleta vai do primeiro ao último dia de cada mês analisado. O IPC da FIPE é dividido em sete grupos: alimentação, educação, habitação, vestuário, transporte, saúde e despesas pessoais. Inicialmente será abordada a interação entre grupo alimentação e o IPC como mostra o gráfico abaixo:

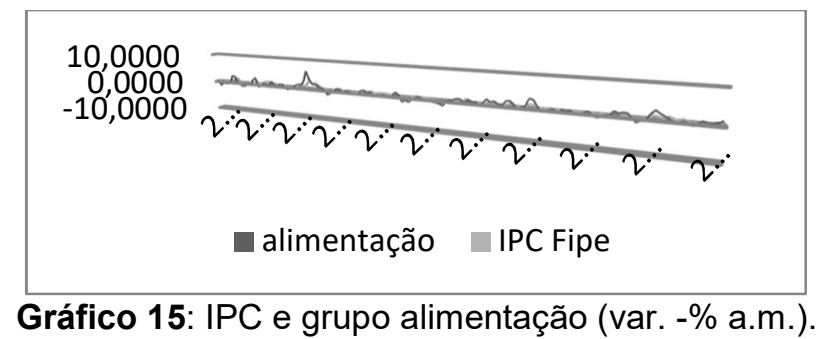


O gráfico 15 revela que nos primeiros anos da década, entre 2000 e 2003, o grupo alimentação, de um modo geral, impactou positivamente no índice inflacionário do IPC, dando destaque para o pico ocorrido em meados de 2002. Após esse período, os preços relacionados aos alimentos apresentam uma queda e mudam sua trajetória para ora caminhar junto com o índice geral e ora exercer pressão negativa, esse movimento vai até o ano de 2006, ao qual o grupo alimentos reverte seu movimento e começa a impactar positivamente o índice de modo significativo. A partir de meados de 2008, o grupo apresenta um arrefecimento até meados de 2010, posteriormente, alterna um forte impacto positivo em 2011 com uma acomodação nos últimos meses. Portanto, a partir dos comportamentos das variações percentuais apresentadas no gráfico, o grupo alimentação aparentemente possui importante parcela na explicação da evolução dos preços no IPC. O gráfico 16 analisa a relação entre o grupo educação e IPC como pode ser observado abaixo:

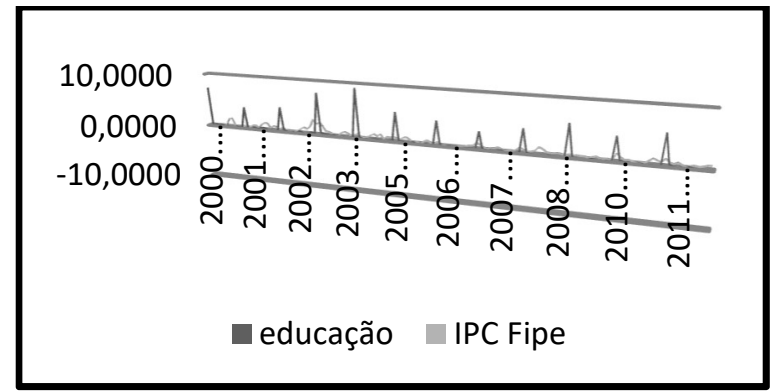

Gráfico 16: IPC e grupo educação (var. -\% a.m.)

O grupo educação apresenta um comportamento de fortes reajustes anuais, como pode ser verificado no gráfico 16, durante todo o período de análise, seguido por uma acomodação e trajetória inferior ao IPC nos demais meses. A seguir será abordada a interação entre os grupos habitação, transportes e o índice completo:

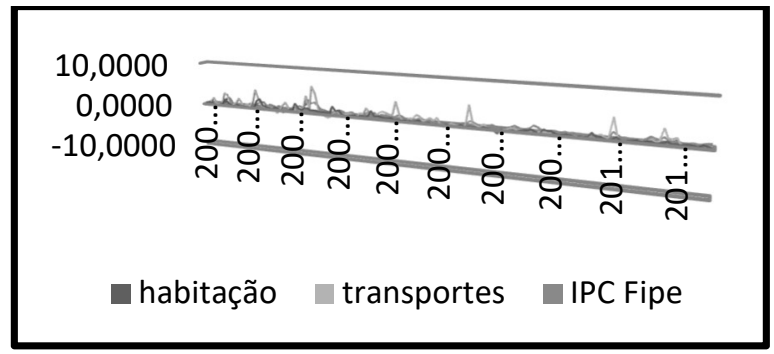

Gráfico 17: IPC, grupo habitação e transportes (var. -\% a.m.).

A partir do gráfico 17, pode ser observada a trajetória do grupo transportes, ao longo do período de análise. O grupo é caracterizado por fortes reajustes sazonais, apresentando um impacto positivo sobre o IPC, do início da década até 2007 , salvo alguns curtos períodos de impacto negativo. De meados de 2007 até final de 2009, apresenta uma evolução abaixo da linha do IPC indicando impactos negativos nesse período. Entretanto, nos anos de 2010 e 2011, ocorrem fortes picos de alta seguidos de arrefecimento e impactos negativos moderados.

Quanto ao grupo habitação, sua trajetória é mais suave que o grupo transportes, pode ser destacado dois períodos distintos. O primeiro do ano 2000 a 2004, salvo alguns impactos 
negativos, o panorama geral foi de impacto positivo em relação ao IPC alternando com momentos de mesma trajetória. A partir de meados de 2004, ocorre uma mudança na evolução do grupo, ao qual passa a exercer impactos negativos ou caminhar junto com o IPC, ressalvados pequenos períodos de alta.

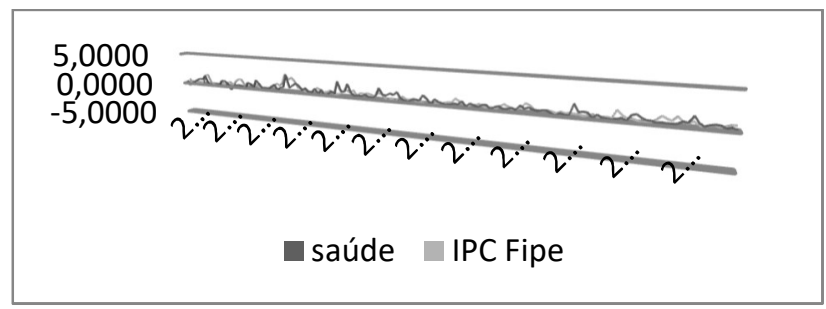

Gráfico 18: IPC e grupo saúde (var. -\% a.m.).

A relação entre o grupo saúde e o IPC é apresentada no gráfico 18. Apesar de alguns reajustes importantes de 2000 até 2004, os preços apresentam um comportamento de impactos negativos no IPC. Já de 2004 até meados de 2006, a evolução do grupo saúde gravitou em patamares superiores ao índice, resultando em impactos positivos, após esse período e até 2009, a trajetória tem comportamento mais moderado e em patamares mais baixos. O final da década é caracterizado por novos picos de reajustes. Porém, cabe destacar um descasamento entre os picos do IPC e do grupo saúde ao longo de todo período analisado. As análises seguintes abordam os agrupamentos despesas pessoais e vestuário em relação ao IPC:

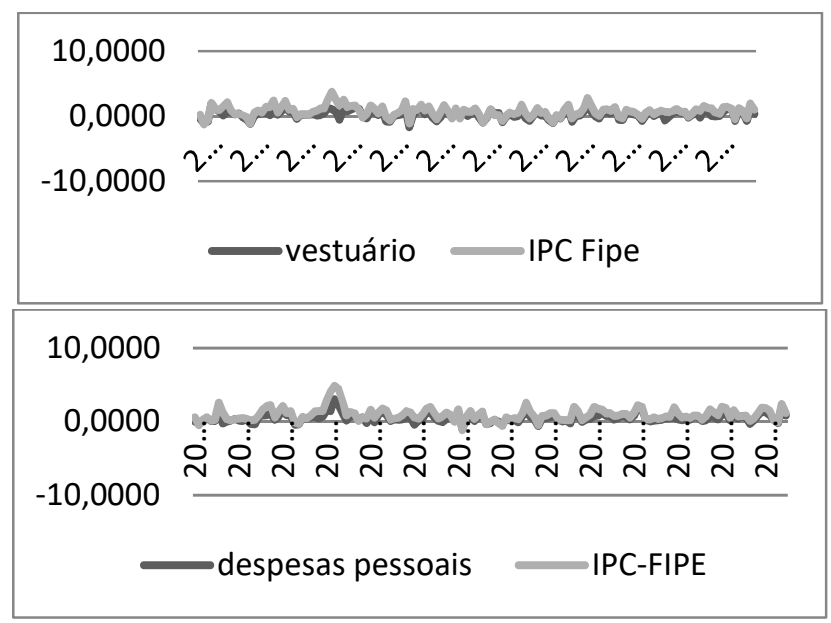

Gráfico 19: IPC, grupo vestuário e despesas pessoais (var. -\% a.m.).

Dentre todos os grupos que compõe o IPC, vestuário e despesas pessoais são os únicos que possuem uma trajetória clara, no sentido de pressionar os preços do índice para baixo, apresentando um comportamento abaixo do índice geral ao longo do período analisado. De um modo geral, é importante destacar que apesar de alternâncias e variações os grupos alimentação, saúde, transporte, habitação e educação apresentaram uma tendência maior no sentido de pressionar para cima o índice de preços ao consumidor que para baixo. Já os grupos vestuário e despesas pessoais possuem um comportamento mais evidente no sentido de impactar negativamente no IPC. 
Realizada a investigação a cerca dos componentes dos principais índices de inflação ao consumidor no Brasil, ao longo da década de 2000, é importante também abordar os índices de inflação no atacado e seus elementos para que se possa ter uma compreensão maior a respeito da dinâmica inflacionária no Brasil, assim, o próximo tópico abordará alguns dos principais índices de preços no atacado e suas composições.

\section{Índices de Preços no Atacado e algumas Composições}

Os preços praticados no âmbito do atacado antecedem o nível varejista e são importantes por apresentarem comportamentos antecedentes ao consumidor. Nessa seção será tomado por base o Índice de Preços no Atacado (IPA), mensurado pela FGV, além de suas variações e componentes. O IPA tem como objetivo mostrar a evolução do nível de preços nas transações interempresariais abrangendo as etapas de produção que antecedem as vendas do varejo, como insumos agrícolas, industriais, bens intermediários e finais.

O Índice de Preços por Atacado Disponibilidade Interna (IPA-DI) objetiva mensurar os preços que antecedem as vendas no varejo. Já o Índice de Preços por Atacado do Mercado (IPAM), também calculado pela FGV, possui as mesmas características do IPA-DI, diferenciando no período de coleta de dados, que vai do dia vinte e um de determinado mês até o dia vinte do mês seguinte. O IPA-M é componente fundamental do IGP-M importante indexador nas atualizações de diversos contratos praticados no Brasil. Agora o Índice de Preços por Atacado segundo estágio de processamento (IPA-EP) é uma abertura do IPA, porém detalhando a evolução dos preços nos diversos estágios de processamento econômico. Após uma breve explicação a respeito dos índices no atacado abordados nessa seção, o gráfico 20 revela a evolução dos preços no atacado de acordo com o IPA-M:

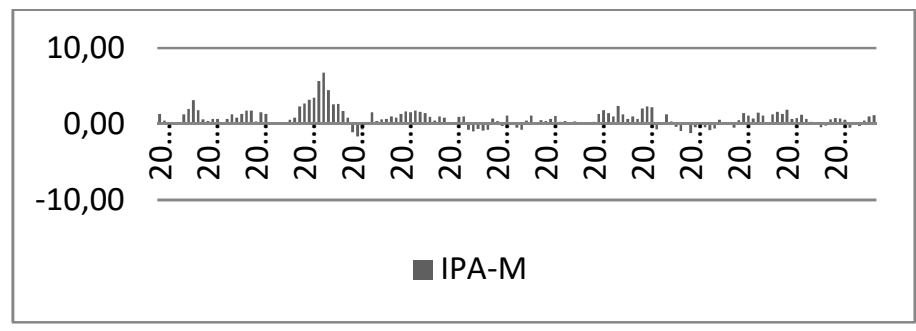

Gráfico 20: IPA-M - (\% a.m.).

Através do gráfico 20 o comportamento do IPA-M pode ser observado. O índice apresenta variações percentuais positivas em quase toda a década, o destaque de alta ocorre no final de 2002, porém também cabe ressaltar que nos anos de 2000, 2007 e 2008 as elevações foram consideráveis. Os impactos negativos foram mais tímidos, porém em meados de 2003, 2005 e 2009 eles se apresentaram de forma mais significativa. Com o propósito de continuar investigando as pressões inflacionárias ao longo da década, no âmbito dos preços no atacado, a tabela 3 , revela o comportamento de dois importantes índices que antecedem as vendas do varejo, o Índice 
de Preços por Atacado segundo Estágios de Processamento e o Índice Geral de Preços por Atacado Disponibilidade Interna, como pode ser observada.

Tabela 3: Índices de Preço Por Atacado 2000 a 2010 - (\% a.a.).

\begin{tabular}{l|ll} 
& $\begin{array}{l}\text { Indice Geral de Preços por Atacado } \\
\text { Disponibilidade Interna }\end{array}$ & $\begin{array}{l}\text { Indice de Preços por Atacado segundo Estágios de } \\
\text { Processamento }\end{array}$ \\
\hline 2000 & 18.11 & 12.06 \\
2001 & 12.60 & 11.87 \\
2002 & 16.66 & 35.41 \\
2003 & 27.56 & 6.26 \\
2004 & 10.46 & 14.67 \\
2005 & 5.57 & -0.97 \\
2006 & 0.81 & 4.29 \\
2007 & 5.60 & 9.44 \\
2008 & 13.71 & 9.80 \\
2009 & -4.08 & -4.08 \\
2010 & 13.85 & 13.85 \\
2011 & 4.12 & 4.12 \\
\hline
\end{tabular}

Os dois índices convergem ao final da década, a partir de 2009, porém os anos anteriores demonstram trajetórias diferentes, nas duas abordagens de cálculo dos índices no atacado pela FGV. O IPA segundo estágios de processamento apresenta uma alta expressiva no ano de 2002 alcançando $35,41 \%$, enquanto o Índice Geral de Preços por atacado disponibilidade interna tem seu ápice em 2003 com 27,56\%. O destaque deflacionário da série ocorre no ano de 2009 com valor de $-4,08 \%$ para os dois índices. De modo geral, os índices no atacado exibem valores relativamente mais elevados em relação aos índices ao consumidor, porém, com trajetórias semelhantes. A análise dos índices puros no atacado é relevante no sentido de observar seus comportamentos e trajetórias ao longo da década, mas para verificar qual setor exerce uma pressão inflacionária de maior ou menor impacto é interessante observar alguns componentes do IPA como mostra o gráfico 21:

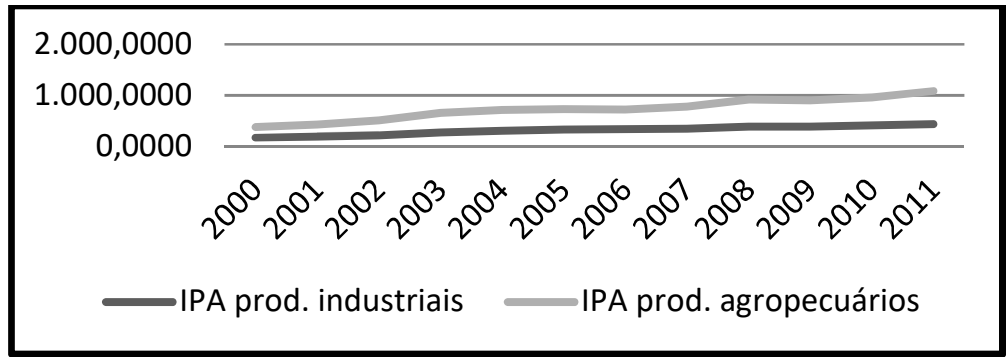

Gráfico 21: IPA, origem - prod. Industriais e Agropecuários - índice (ago. $1994=100$ )

O gráfico 21 mostra a trajetória em índice do IPA produtos industriais e o IPA produtos agropecuários. A evolução dos preços no setor agropecuário ocorre de modo excessivamente mais elevado, se comparado com os produtos industriais, o IPA agropecuário apresenta valores inferiores a 400, no inicio da amostra e termina superior a 1000, já o IPA produtos industriais sai de valores inferiores a 200 chegando a ultrapassar levemente a casa dos 400. Desse modo, os Índices de Preços Por Atacado no Brasil na década de 2000 apresentaram trajetórias semelhantes aos Índices de Preços ao Consumidor, porém em patamares mais elevados. Quanto à análise dos 
componentes do IPA, destaque para os produtos agropecuários, ao qual tiveram uma evolução expressiva em relação aos produtos industriais.

\section{CONCLUSÕES}

Esse artigo teve por objetivo investigar os principais índices de inflação no Brasil, bem como seus grupos, subgrupos e importantes desagregações, a fim de verificar quais os componentes mais pressionaram os níveis de preços no Brasil na década de 2000. Primeiramente, foi traçado um panorama geral de importantes índices de inflação no país com diferentes metodologias e instituições, considerando os preços ao consumidor, por atacado e setoriais. As variações percentuais revelaram que no início da década, principalmente de 2001 até 2003 os índices de inflação, de um modo geral, se situaram em níveis mais elevados que na média do período. Os diferentes índices de preços ao consumidor apresentaram trajetórias semelhantes, ao menos nos picos e vales, demonstrando uma forte pressão inflacionária no ano de 2002 e um arrefecimento no ano de 2006.

Uma explicação a ser considerada está relacionada com a taxa de câmbio que influencia a inflação basicamente pelos custos de produção, bens finais importados e comercializáveis. É importante ressaltar que no período de 2001 até 2003, no qual, os índices apresentaram seus maiores valores, a taxa de câmbio também esteve em patamares elevados. Entretanto, no ano de 2008, a desvalorização cambial não acarretou o mesmo efeito do início da década, talvez por pressões deflacionárias de outros componentes dos índices não diretamente afetados pela taxa de câmbio.

Foi observado também um aumento expressivo das commodities e consequentemente do preço da cesta básica, porém, uma afirmação categórica a respeito do impacto da alta dos preços das commodities sobre o nível de inflação é bastante complexo, principalmente no Brasil que é um grande exportador nessa área. Isso porque é necessário separar os efeitos das elevações nos preços dos alimentos e demais produtos relacionados diretamente com as commodities, do efeito indireto que ocorre devido à apreciação cambial que essas exportações podem provocar. Além disso, o salário mínimo real juntamente com sua paridade de poder de compra em dólar subiram durante todo o período analisado.

Quanto à análise dos índices e de seus componentes propriamente dito, os preços por atacado no Brasil, IPA-M, IPA-EP e Índice Geral de Preços por Atacado Disponibilidade Interna, apresentaram trajetórias semelhantes aos índices de Preços ao Consumidor, porém em patamares mais elevados. Já na análise dos componentes do IPA, destaque para os produtos agropecuários que tiveram uma evolução expressiva em relação aos produtos industriais.

$\mathrm{Na}$ abordagem do IPC-FIPE, é importante destacar que apesar de alternâncias e variações os grupos alimentação, saúde, transporte, habitação e educação apresentaram uma tendência maior, no sentido de pressionar para cima o Índice de Preços ao Consumidor, que para baixo. Já 
os grupos vestuário e despesas pessoais possuem um comportamento mais evidente no sentido de impactar negativamente o IPC.

A análise do INPC pode ser divida em dois grupos, o primeiro, apesar de alternar momentos de pressão inflacionária e arrefecimentos, exerceu pressões positivas sobre o INPC ao longo da década, são eles: alimentos, saúde, educação, habitação e transportes. Já o segundo grupo exerceu um comportamento claro no sentido de exercer impactos negativos no índice cheio, são eles: vestuário, artigos de residência, despesas pessoais e comunicação.

Já na análise do IPCA, os preços administrados foram os mais significativos pressionando a inflação no período de 2000 até 2005 , apresentando $14,7 \%$ no ano de 2002, enquanto os serviços subiram apenas $5,5 \%$ nesse mesmo ano. O segundo maior grupo que mais impactou o nível de preços no período de 2000 até 2005 foi o dos alimentos e bebidas. Seu pico foi ainda maior que o dos administrados no ano de 2002 alcançando 20,7\%. Os preços industrializados apesar de uma aceleração em 2001 e 2002, talvez fruto da depreciação cambial do período, fica em terceiro lugar a frente somente do grupo serviços, que aparece, nessa abordagem como o grupo de menor pressão inflacionária no IPCA.

A partir do ano de 2006, na segunda metade da década, os preços dos administrados sofrem um arrefecimento e o grupo alimentos e bebidas passam a exercer a maior pressão inflacionária do período. Os preços das commodities sofrem fortes altas nos mercados internacionais, esse fenômeno pode explicar parte das elevações nos preços dos alimentos no país. Após 2006, as variações do grupo alimentos e bebidas atingiram patamares superiores a $10 \%$, salvo 2009 , é importante também destacar que o grupo serviços apresentou um valor elevado de 7,6\% em 2010. Os preços industriais tiveram valores relativamente baixos em 2006 com $1,4 \%, 2007,2,1 \%$, e $2009,2,8 \%$.

De um modo geral, no período de 2000 até 2010, o grupo dos preços administrados foi o que mais pressionou o índice de inflação para cima, seguido de alimentos e bebidas. Apesar de no último ano da série os serviços darem indícios de aceleração, o grupo junto com os preços industriais apresentou evolução em patamares abaixo dos dois primeiros. Numa abordagem geral, os movimentos do IPCA e seus componentes são os mais representativos do que ocorreu com a inflação brasileira na década de 2000. Os preços administrados tiveram papel fundamental no comportamento da inflação, principalmente na primeira metade da década, após esse período o grupo alimentos passa a pressionar os preços de modo mais significativo. É importante salientar as limitações em trabalhos destas características, portanto seria interessante analisar a temática da inflação no Brasil, por meio, de outras metodologias e amostras.

\section{REFERÊNCIAS}

BARBOSA-FILHO, N.. Inflation targeting in Brazil: 1999-2006. International Review of Applied Economics, v.22, n.2, 2007.

FERRARI FILHO, F.; ARESTIS, P.; PAULA, L. F.. A nova política monetária: uma análise do regime de metas de inflação no Brasil. Economia e Sociedade, Campinas, v.18, n.1, p.1-30, 2009. 
MODENESI, A. M.. Regimes Monetários: Teoria e a Experiência do Real. Barueri: Manole, 2005.

OREIRO, J. L.; PUNZO, L.; ARAÚJO, E.; SQUEFF, G.."Restrições macroeconomias ao crescimento da economia brasileira: diagnósticos e algumas proposições de política”. São Paulo: FGV, 2008. 